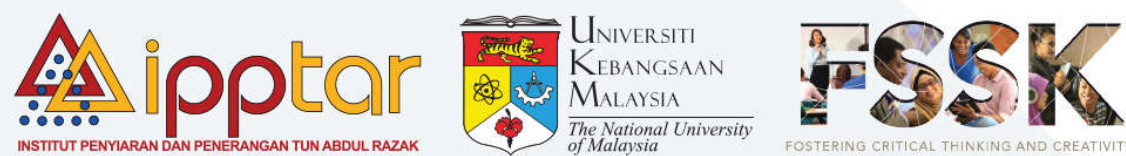

\section{P R O C E E D I N G S}
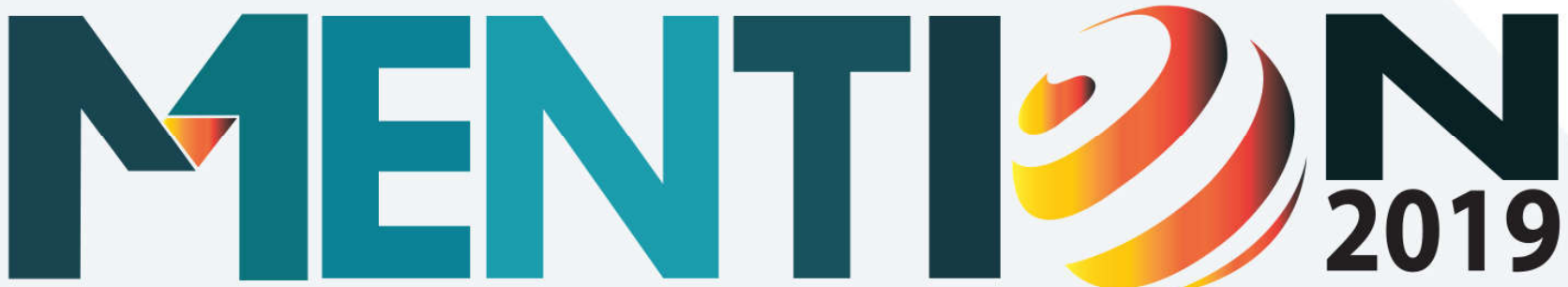

INTERNATIONAL CDNFERENCE QN MEDIA AND CDMMUNICATION

ISBN 978-983-9391-72-5

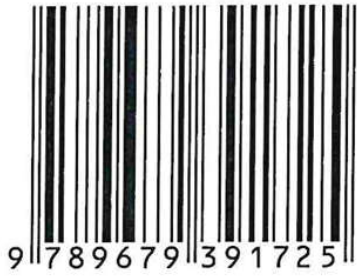


First published 2019 by Centre of Research in Media and Communication, UKM

(C) Centre of Research in Media and Communication

All rights reserved. No part of this publication may be produced, stored in retrieval system, or transmitted, in any form or by any means, electronic, mechanical, photocopying, recording or otherwise, without the prior permission of the Centre of Research in Media and Communication, UKM

ISBN 978-983-9391-72-5

Cover design $\quad$ : Institut Penyiaran dan Penerangan Tun Abdul Razak (IPPTAR)

Typesetting : Jamali Bujang Sanawi

Typeface : Times New Roman

Typesize $\quad: 16 / 12$

Published by

Centre of Research in Media and Communication

Faculty of Social Sciences and Humanities

Universiti Kebangsaan Malaysia

43600 UKM Bangi, Selangor, MALAYSIA

Tel: +60389214277

Fax: +60389213542

Email : mention@ukm.edu.my 


\title{
Reliance, Media Exposure and Credibility
}

\author{
Syed Arabi Idid \\ International Islamic University Malaysia \\ sarabidid@iium.edu.my \\ Shahrul Nazmi Sannusi \\ Universiti Kebangsaan Malaysia \\ nazmy@ukm.edu.my \\ Mohammed Fadel Arandas \\ m.hd1987@hotmail.com
}

\begin{abstract}
This study discusses credibility of both the traditional and social media from the audience perspective. Numerous definitions and conceptualisations of media credibility are either source or medium based but there are also numerous measurements made on the concept that gave rise to varied findings. An attempt was made to associate the concept of credibility with media exposure, postulating that the greater use of media would mean greater credibility. Two studies were made involving a total of 4095 respondents with 1544 questionnaires distributed in April 2019, and 2551questionnaires in January 2018 to investigate the concept of credibility and its correlate with media use. The first period was before the General Elections but the April 2019 study was made after the May General Election giving an idea how credibility could have changed under a new government. The results of this study revealed that Malaysians perceived the traditional media, including TV, radio, and newspapers, were more credible than the new media (internet, online news portals, Facebook, and Twitter). TV was perceived to have the highest credibility, while Twitter, the lowest credibility. The social media suffered low credibility due to the surrounding discussions on fake news, false information, and post-truth issues. The sources of content in the traditional media are mostly known or verified, unlike that of the new media, thus paving for the poor evaluation of credibility of the new media.
\end{abstract}

Keywords: Media credibility, traditional media, new media, media exposure, Malaysia.

\section{OBJECTIVE}

This paper will discuss credibility as a correlate for media use or exposure suggesting that a higher level of credibility will be associated with a greater media use. It will distinguish between the dimensions of media credibility and the forms of media in predicting for media exposure. Several studies have been conducted on understanding 
the concept of credibility but more often than not the discussion has focused more on the perceived credibility of source. This paper focuses on the audience perception of credibility and their use of the different forms of media. It will discuss whether there is a differential perception of credibility and exposure among users of the social and traditional forms of media.

\section{MEDIA EXPOSURE}

Reliance on the media is said to be correlated with the accepted credibility of the media. When audience members perceive a specific media to be highly credible, they will depend on that media for information, and this in turn will make them to be more reliant. If there is credibility of media then it will lead to greater use and reliance on it, thus paving the way for greater media exposure. This reasoning begins from media as the agent for prediction. One must accept media credibility to explain for media use or media exposure. The findings show that dependency on media is influenced by the perception of individuals about the credibility of media, so credibility is derived from media reliance (Wanta $\& \mathrm{Hu}, 1994$ ). The higher the media use the higher would be credibility of media. The more a person uses a particular medium, the higher is the probability that person will input greater credibility toward the media in use. Those who prefer and use a specific medium more than other media as their main source of news tend to consider it more credible (Westley \& Severin, 1964).

Exposure to a newspaper is considered a strong predictor for the credibility of that newspaper (Armstrong \& Collins, 2009). There is an association between use of newspaper and credibility, supporting the assumption that those who use specific source tend to consider it as credible (Yamamoto \& Nah, 2017). However, most people tend to expose to another media after exposing their preferred media choice for seeking the truthfulness and authentication of a news story (Adeyanju, 2015).

While a general use of media is being postulated, it can also mean perceived credibility being associated with specific medium or media type. Although generally, frequency of use is not correlated with newspaper or TV credibility, yet measures of media choice are linked to higher ratings of credibility. Television or newspapers users are mostly those who have a higher rating of media credibility than those who have less use of these media (Rimmer\& Weaver, 1987). Hence the use of media has an influence on the perceived credibility of media or a specific media type by people make them perceive it as more credible than other people who do not use that media often (Oyedeji, 2011).

"Exposure" is defined in various ways. Slater (2004) defines it as the extension of encountering particular messages, message classes, or media content by the audience members. Exposure refers to merely encountering the messages by people, irrespective whether those messages were given due attention or were able to be recalled. Other variables such as involvement with the topic or prior knowledge that may predict attention to the message's content is also being used as part of exposure.

Media exposure is also meant to be any the opportunity for a listener, viewer, or reader 
to hear or see a message in specific medium. Using several types of media refers to serve several functions such as involving audience in several ways, and having varied credibility level (Qader \& Zainuddin, 2011). There is ambiguity about the mode of media exposure mode including its extensity and frequency that could produce a different effect on issue at the personal or societal level (Li, 2018)

The study of Fishbein \& Hornik (2008) discussed the effects of media exposure on the beliefs, behaviours, attitudes, and intentions of the people who are exposed to the media. Webster (2016) discussed that exposure as a reason for political and social effects, and it is affected by a host of psychological and social factors. Studying the exposure measures is important not only in assessing their relationship with other variables and accuracy, but for understanding the wide social consequences of why and how they are used.

For a long time, measuring the exposure to the media content of media was a challenge as it is important to understand the effects and use of media. In the current media landscape, the measurement of media exposure became more complicated due to exposure by individuals to diverse messages anywhere, anytime from different media platforms and various sources. The media exposure measurement is a critical issue for uses and effects in several fields such as in communication, political science, economics, psychology, and sociology (de Vreese \& Neijens, 2016).

This equation does not explain the concept of credibility. What makes for credibility? There are scholars who found that use of media is a predictor for the credibility of news. This reasoning runs opposite to earlier findings on credibility as a predictor for media use. The findings by Cheng \& Lo ( 2012) turns the argument around positing that the more the media use, the higher would be the credibility of the media.

\section{CREDIBILITY}

There is yet another dimension of understanding credibility. Possible factors that might affect perceptions of news credibility are interpersonal news discussion and use of media (Kiousis, 2001). If individuals have motives in exposing to the medium other than just providing information, this knowledge itself will heavily influence their exposure and evaluation decisions (Johnson, 1984).

Studying credibility in general, and credibility of media in specific, face a real suffering from coherence that is lacking among the researchers. This has caused two particular problems: lacking a clear definition of credibility and lacking a clear method for measuring the concept. Credibility is an important research area in both communication and persuasion research (Appelman \& Sundar, 2016). The academic literature on credibility mostly came from communication and psychology fields, and dates back to the 1950s. It is generally agreed that credibility is considered as perceived quality, and it doesn't reside in a piece of information, a person, or an object (Tseng \& Fogg, 1999). 
While we have discussed credibility found among the media, we are yet to discuss the constituents of credibility. Some scholars (Edelstein \& Tefft; 1974; Flanagin \& Metzger, 2007; Idid \& Wok 2006; Jackob, 2010; Metzger and Flanagin 2008; Morris, Counts, Roseway, Hoff \& Schwarz, 2012; Tseng \& Fogg, 1999) have found credibility to be similar to trust or believability, but others have gone beyond the single dimensions, by providing the idea that credibility is a multidimensional concept.

It is assumed that credibility is implicitly dichotomous both low or high, unidimensional, and specifiable regarding objective source characteristics. This condition means that the variable is less or more static source attribute, instead of a perception that is subject to change (Berlo, Lemert, \& Mertz, 1969). The credibility criteria and predictors may depend on the perspective of receiver on the medium. From the perspective of receiver credibility is defined as the extent individual judges his or her perceptions to be a valid reality (Newhagen \& Nass, 1989).

Metzger and Flanagin (2008) viewed that "credibility is the believability of a sourceor message, which is made up of two primary dimensions: trustworthiness and expertise" Gaziono and McGrath (1986), on the other hand, stated that the definition of credibility is different and depended on the approach of the study that is being conducted. And there are 12 credibility factors that can be used to measure credibility which are "fair", "unbiased", "tells the whole story", "accurate", "respect people's privacy", "watch out after people's interests", "concerned about the community's well-being", "separate fact and opinion", "can be trusted", "concerned about the public interest", "are factual", and "has well-trained reporters". These factors are represented as concepts that indicate credibility and the respondents need to rate stated characteristics using a 5-point scale, represented by 1 as the lowest possible rating and 5 as the highest rating.

Edelstein \& Tefft (1974) used believability alternatively with credibility, and generally considered the term to be to source credibility. Also, credibility has been defined as believability; credible information or people are believable people (Tseng \& Fogg, 1999). As applied to the news story, credibility concept can be defined as a global evaluation of the story objectivity (Sundar, 1999). Additionally, Bucy, D'Angelo \& Bauer (2014) defined credibility as the quality of being worthy of trust or believable. Credibility is defined as a perceptual variable instead of an objective measure of the some information source or information quality (Flanagin \& Metzger, 2007).

Tseng \& Fogg (1999) listed four credibility types: (1) presumed credibility focuses on the degree of belief by the perceiver to something or someone because of general assumptions in the mind of perceiver; (2) Surface credibility focuses on the degree of belief by the perceiver to something or someone according to simple inspection; (3) Experienced credibility refers the degree of believe by the perceiver to something or someone based on first hand experience; and (4) Reputed credibility describes focuses on the degree of believe by the perceiver to something or someone based on the report of third parties. 
Finally, Francke \& Sundin (2012) have identified four concepts of credibility which are: (1) associated with the source stability and control; (2) credibility as perceived as partial and situational more than absolute; (3) credibility is associated with democratic production forms and voices multiplicity; and (4) supporting the claim from several sources several sources support the claim strengthen the credibility.

\section{MEDIA CREDIBILITY}

In research of mass communication, media credibility is considered as one of the most widely studied areas, which is contradictory and confusing topic to many scholars, policy makers, and journalism professionals (McGrath \& Gaziano, 1986). Thus, it is needed to measure and define media credibility in a different way from general credibility; there is a need to consider the possibility of confusion for the source, medium, and message credibility (Appelman \& Sundar, 2016). It seems that media credibility is a part of connected net of audience attitudes toward media, so it might be more fruitful to examine it as a part of entire net more than as an isolated segment only (Starck, 1969).

Since the earliest days of mass communication field, credibility research was a main part of communication scholarship. Generally, credibility concept has been studied in two main areas: source and medium credibility. Source credibility has been studied in organizational, interpersonal, and mass-mediated contexts. Medium credibility has focused on the delivery channel of content more than sender/s of the content (Kiousis, 2001).

Four different media credibility sources have been identified by Atwood (1985) which were: (1) the original details provider; (2) the by-lined writer; (3) the news service; and (4) the station whether TV, radio, newspaper or magazine. Generally, the influence of message on source credibility would be greater than the influence of source credibility on message.

Besides being a psychological characteristic, credibility is a communication variable too. Credibility is part of a two-way interaction between receivers and communicators of message and a dynamic entity that arise from the transaction between audience member and source. It is found that concept of credibility is not unitary or simple, but it has more than a single layer or one dimension. A credible communicator is the one who shows goodwill toward audience members, and who is considered as trustworthy, and perceived as an expert (Perloff, 2003).

Media credibility includes medium qualities that spread messages such as newspapers and television (Yamamoto \& Nah, 2017). The items of media credibility and hence their possibility to influence behaviour and attitudes, largely depends on the availability of other information sources to individual consumers and the experience quality that people gain in their daily life (Meyen \& Schwer, 2007). 
Another set of findings relate to the concept of trust which was made to find equivalence to credibility. A dependency on the media expresses significantly a higher trust level among those individuals. One of the reasons for using alternative sources of information is the trust in media. Trust in media is caused by feeling of dependency on it, and trusting specific media could lead to exposure and then to media dependency (Jackob, 2010). Thus audience members depend on the media and in their dependence they have a higher trust. But if Trust as a concept is equivalent to Credibility then one can posit the higher dependency on the media with credibility or with its equivalence, dependency.

The trust relationships is influenced by credibility of media source based on the correlation between media credibility and trust relationships. Practitioners of public relations may be advised for investing more time in placing credible and objective information in key traditional media to start, nurture, and protect trust relationships with a strategic public (Jo, 2005).

Types of media will influence media credibility. A positive association has been revealed between the use of television news, and perceived media efficacy and credibility of audience and the intention for media participation. On the other hand, no relationship was found between the use of newspapers and the perceived media efficacy and credibility of audience (Shen, Lu, Guo \& Zhou, 2011). So audience belief that television has more credibility than newspapers. Reliance on both traditional and online sources of information seems to be stronger predictor for credibility. There was better prediction of credibility of for online newspapers and television by reliance on traditional media than their online counterparts. As significant sources for political information, online media news became more important and credible than traditional media news (Kim \& Johnson, 2009).

Reliance on the online counterpart of traditional media appears to have a stronger predictor of credibility than Web in general. The reliance of online media sources was more on the counterpart of traditional media than the reliance on the Web (Johnson \& Kaye, 2000). There is an association between education, age, internet use with assessment of credibility by internet users (Poler Kovačič, Erjavec\& Štular, 2010). Reliance on traditional and online media is considered a stronger predictor of online sources credibility. Distributing the substantive content on twitter such as breaking news has increased the significance of assessing the tweets credibility. Assessing the credibility of tweets by users is depends on the trust relationships with the authors of those tweets. When the source of tweets is not from the people that the users follow, then those users become concern about the credibility of that content (Morris, Counts, Roseway, Hoff \& Schwarz, 2012).

A study on communication professionals revealed that credibility is predicted by the use of blogs. Blogs were found to be more credible by both public relations and journalists practitioners. Information on blogs was found to be more credible by professionals who used blog regularly for surveillance purposes and non-interactive research. Therefore, among communication professionals, credibility of blogs should be increase if the readership of blogs continues to increase. Additionally, blogs have 
been found more credible by younger professionals in both public relations and journalism (Sweetser, Porter, Chung \& Kim, 2008).

\section{Source Credibility}

Source credibility or "ethos" has received much attention from mass communication researchers. Historical conceptualizations of the construct of source credibility have not been challenged in a serious way and that construct sufficient measures are available. Source credibility or "ethos" construct has been plenty defined in the past (McCroskey \& Young, 1981). Credibility came from Aristotle, who has formulated the term ethos to describe the source qualities that simplified persuasion (Perloff, 2003).

In communication process, source credibility is a significant factor, and its literatures mostly focus on the persona. Viewing credibility must be from an extended perspective, especially when recognizing the source as multidimensional (Bae, Wright \& Taylor, 2001). Much of source effects research has been derived from interpersonal communication more than mass communication settings (Edelstein \& Tefft, 1974). Research of source credibility concentrates on message source characteristics such as the, organization, the speaker or the news organization, (Golan, 2010). Sources contain a wide range of message senders such as: news organizations, news anchors, and Websites (Yamamoto \& Nah, 2017).

Credibility of source is the amount of believability or credibility referred to a source of information whether an individual or a medium by the receivers (Bracken, 2006). The term of source credibility is mostly used to imply the positive characteristics of communicator that influence message acceptance by receiver. Credible sources were more persuasive than the low credible sources (Ohanian, 1990). Communication and source credibility are strengthening the effect perception of a print-media communication. The main influence of source credibility was found for understood accuracy of the article regardless of communication strength (Kaufman, Stasson \& Hart, 1999).

However, expertise and trustworthiness were identified as two main dimensions of source credibility (Hovland and Weiss, 1951). The study of Berlo, Lemert, \& Mertz (1969) has extended Hovland and his colleague study on source credibility through investigating the criteria that actually used by receivers to evaluating message sources, and they found that three dimensions were isolated: safety, dynamism, and qualification.

Low source credibility may be one previous condition that serves for immunising the beliefs of an individual and thus make him resist more to persuasion. The persuasive message which is attributed to a low credible source might be considered as unreliable prior to its presentation by the audience (Greenberg \& Miller, 1966).

Producing reliable-effectual content of newspapers requires understanding credibility. 
Evaluating the news articles credibility comes through three frames message, media, and source. The credibility of the message has a positive association with media and source credibilities. The newspapers influence source credibility significantly (Srinivasan \& Barclay, 2017).

\section{Message Credibility}

Message credibility is concentrating on messages characteristics that could make them less or more credible. Message credibility examines how message characteristics influence believability whether of the source or of the message of source (Metzger, Flanagin, Eyal, Lemus \& McCann 2003). In the news context, the measurement of message credibility can be through asking participants to rate to which degree the content is believable, authentic, and accurate. Based on that, message credibility can be measured as the judgment of an individual about the accuracy of communication content (Appelman \& Sundar, 2016). Finally, when applying message credibility to news that should concerns the news characteristics or the credibility degree of news stories (Yamamoto \& Nah, 2017). Medium credibility research concentrates on the medium through which the message is delivered such as TV compared to newspaper (Golan, 2010).

\section{TRADITIONAL AND NEW MEDIA CREDIBILITY}

For several decades, the major source for spread information was the mass media such as $\mathrm{TV}$, radio, newspaper, and magazine, and they have played an essential role as a societal watchdog and "fourth estate of the realm" (Adeyanju, 2015). Currently, the audience has several choices to seek information, they can select print media or broadcast or even online media. Once there are greater choices online; the audience can seek the information from trusted source rooted such as traditional journalism, or seek the information from independent producers of media, or from "gatewatchers" who watch the gatekeepers (Banning \& Sweetser, 2007).

A survey managed by the American Society of Newspaper Editors (ASNE) used a set of operational credibility definitions, including narrow and wide measures. To a certain degree, the result suggested that the attitude of respondents toward TV and newspaper was similar, and both credibility scores for TV and newspaper have a moderate correlation with each other (Gaziano \& McGrath, 1986).

The results by Tanta, Barić-Šelmić \& Levak (2017) revealed that traditional media especially the printed one is more credible than the new media due to their way and approach of discussing the issues. The diffusion and popularity of both types of media mostly depend on their credibility and social responsibility. Older journalists have scepticism about the credibility of online information since disseminating false and incorrect information still have a presence on the Internet despite the attempts of online sites on their platforms to counter-attack these fake news (Vergeer, 2018). 
Baxter \& Bittner (1974) applied the study on college students Television is perceived to be the highest credible source of news and radio perceived as the lowest credible source. That might be attributed to the fact that the exposure of TV by college students began since birth. Series of studies which started since 1959, followed by 1963, 1974, 1976 which showed that TV had increasingly become the most dominant and believable and credible medium in lives of people. Television remains the most credible and major source of news for American people (Roper, 1978). The study of Abel \& Wirth (1977) suggested that television is considered more truthful, credible, and significant source than the newspaper regarding local news. However, the results section of this study will show the consistent outcomes with these previous studies.

On the other hand, findings of Kiousis (2001) suggested that people mostly are doubtful about the retrieved information from online, newspapers, and Television news, but newspapers have been rated with high credibility, followed by online and television news respectively. The study of Flanagin \& Metzger (2000) mentioned that Internet information is considered a credible as the information obtained from Radio, TV, and magazines, but not more credible than information from newspaper.

The judgment on TV credibility by people is different from judgment on newspapers. The judgment on TV is related to the immediate and dynamic television nature. Whereas, the judgment on newspapers is related to separation in space and time between readers and producers of newspapers which lead to perceive the newspapers as an organizational unit more than a set of individuals (Newhagen \& Nass, 1989).

Currently, studying media credibility is one of best examples showing the sustained research effort that resulted in cumulative knowledge growth. Approaching television by people is for entertainment and approaching newspapers for information seeking. When people are in entertainment mode they less concentrate to discover and find the errors, than if they are in information processing mode (Mulder, 1980).

Both technological and structural features are considered as factors influencing media credibility. Technological features: Initially, there was a thought that the ability of having live coverage by TV is considered as disadvantage since it would come at accuracy expense comparing to newspapers. Structural features: it is proposed that high perceived believability of television might be referred to the structure of television and industries (Metzger, Flanagin, Eyal, Lemus \& McCann, 2003).

A comparative study has investigated the news credibility of television and newspapers and social media, suggested that educational and knowledge level of internet has impact on believability and selection of news by respondents. Another reason for considering news of television and newspaper are more credible than social media is that they are protection is by well trained personnel and they filter news stories to ensure both objectivity and accuracy (Adeyanju, 2015).

Mass-mediated communication is rooted in its medium. The judgment on a newspaper 
news story and the perception of public is based on the perception of that newspaper, story reporter, editor, and publisher. At the same time, publishing the same news story in a different newspaper might be judged and perceived differently based on the newspaper story itself even if both of newspapers includes the same message and related to the same reporter (Appelman \& Sundar, 2016).

Data from a community survey in the United States show that structural pluralism is negatively related to local newspaper credibility. Data also reveal that social and political trust, use of newspaper, and ideology of conservative are significantly related to credibility of local newspaper. Decreasing of credibility undermined the newspapers role in inform citizens about public affairs (Yamamoto \& Nah, 2017). Another study, suggested that imbalanced structure of news story in a newspaper directly led to perceived story bias, which in turn led to evaluate of the newspaper credibility in a negative way (Fico, Richardson \& Edwards, 2004).

Considering credibility became a necessity with the new context of the Internet growth. None of traditional Internet sources considered somewhat less credible than all other sources of news (Melican \& Dixon, 2008). Credibility is a significant for the Internet since people mostly pay more attention to the media which perceived as credible. Both online and traditional versions were judged as somewhat credible (Johnson \& Kaye, 1998).

Regarding websites, there was a difference in credibility perception from news organization websites and personal websites, the study shows that organization websites were higher in credibility than personal websites in terms of overall site credibility, message, and sponsor (Flanagin \& Metzger, 2007).

There is deference among online media itself based on perceptions or users and credibility which is based on the media technological affordances. it means that not much credibility is added for "being online" if there is no employment for hyperlinks for extending access to related users and topics fail for choosing multimedia features, actively respond to content, and controlling the flow of additional information(Chung, Nam \& Stefanone, 2012).

Regarding credibility of tweet, readers use set of features for making decisions. It has been found that readers look after to be more trusting, maybe because of the limited explicit information available about author on Twitter (Shariff, Zhang \& Sanderson, 2017). There was association of credibility rating with other variables of twitter use, including positive attitudes about instructors who's frequently tweet and use Twitter (DeGroot, Young \& VanSlette, 2015).

\section{MEDIA CREDIBILITY STUDIES IN MALAYSIA}

There was concern on media credibility since the more creditable media has more 
influence on the audience. Media credibility is the believability degree of information source as understood by the audience. Credibility means the quality of broadcasted or written report. Credibility is influenced by many factors such as accessibility, objectivity, elative expertise, report currency, and freedom to report. When assessing the information credibility there should be a consideration for these factors (Idid \& Wok 2006).

In Malaysia, journalism credibility, ethics, and standards have been discussed within the context of corporate interests, political expediency, and controlling the media by laws (Anuar, 2010). The study of Azlan, Rahim, Basri, \& Hasim (2012) about Malaysian mainstream newspapers revealed that the press failure to communicate, inform, and encourage citizen participation among people could cause a damage to the credibility of the local press.

In Malaysia, the declining circulation of mainstream newspapers is related to the credibility of those newspapers. Malaysian people depend less on the media as they do not perceive it as credible. However, the study shows that television appeared to be more credible than Internet which needs to improve its credibility (Salman, Ibrahim, Abdullah, Mustaffa \& Mahbob, 2011). Mustaffa, Ibrahim, Samani \& Rahim (2010) conducted a study on audience perception media credibility in newspaper, television and internet by using credibility scale by Gaziano and McGrath (1986). Their research findings showed that the credibility among traditional media still reached higher proportion rather than new media. This research showed that Malaysians was still depended on traditional media such as newspaper and television rather than internet.

Another study by Mehrabi, Hassan \& Ali (2009) conducted at Universiti Putra Malaysia showed that television was more credible than Internet. Also there was a positive significant relationship between media usage, media reliance, and issue salience with perception of the television and Internet credibility. Wok, Tamam \& Bolong (2010) study about credibility in Malaysia shows that Malaysian youth perceived TV as the most credible media followed by newspapers and Internet respectively. The study also revealed a positive relationship between consumption of TV news and perceiving TV as a credible media.

\section{METHODOLOGY}

A survey was conducted nation-wide as part of the objective to gauge Malaysian perceived credibility of the traditional and new media that they use. It was also to find out whether there were changes in the credibility of the media before and after the General Elections of 2018. A total of 4095 questionnaires were distributed in two years, 2551 questionnaires in 2018, and 1544 questionnaires in 2019. Figure 1 shows the credibility of both traditional and new media in two years.

The survey asked the respondents to provide an answer based on a five point likert scale on how much credibility they had of the media that they used, 1 being the high less trust to 5 most trust of the specific medium given. 


\section{RESULTS}

In both the studies, the respondents placed a high level of credibility on the traditional media than the new media. The TV was most credible with $73 \%$, followed by newspaper and radio with $63 \%$ and $62 \%$ respectively. Then, the internet was the most credible among the new media with $50 \%$. The online news portals figured $44 \%$, followed by $43 \%$ for Facebook and $26 \%$ for Twitter.

In general terms, TV had the highest credibility while twitter was given the least rating at 11 percent.

A total of 70 percent placed credibility on TV in 2019 and 2018. Then, newspapers and radio shaped the same percentage of credibility with $65 \%$ for each. Same of 2018, the internet was the most credible new media in 2019 with 53\%. Then the online news portal figured $49 \%$ of the responses, followed by $48 \%$ for Facebook and $33 \%$ for Twitter.

For both 2018 and 2019, the TV was the most credible medium while Twitter was the least credible sources of information. The results revealed an increase of credibility of all the media platforms from 2018 to 2019 except the TV which has a slight decrease by $2 \%$. Additionally, the credibility of newspaper was highest than radio in 2018 , but in 2019 both newspaper and radio have achieved the same credibility percentage.

In total, it can be seen that traditional media including TV, newspaper, and radio achieved higher credibility than the new media including internet, online news portals, Facebook, and Twitter. On the other hand, the results revealed that there was an increase in the media credibility in Malaysia after the $14^{\text {th }}$ General Election Malaysia.

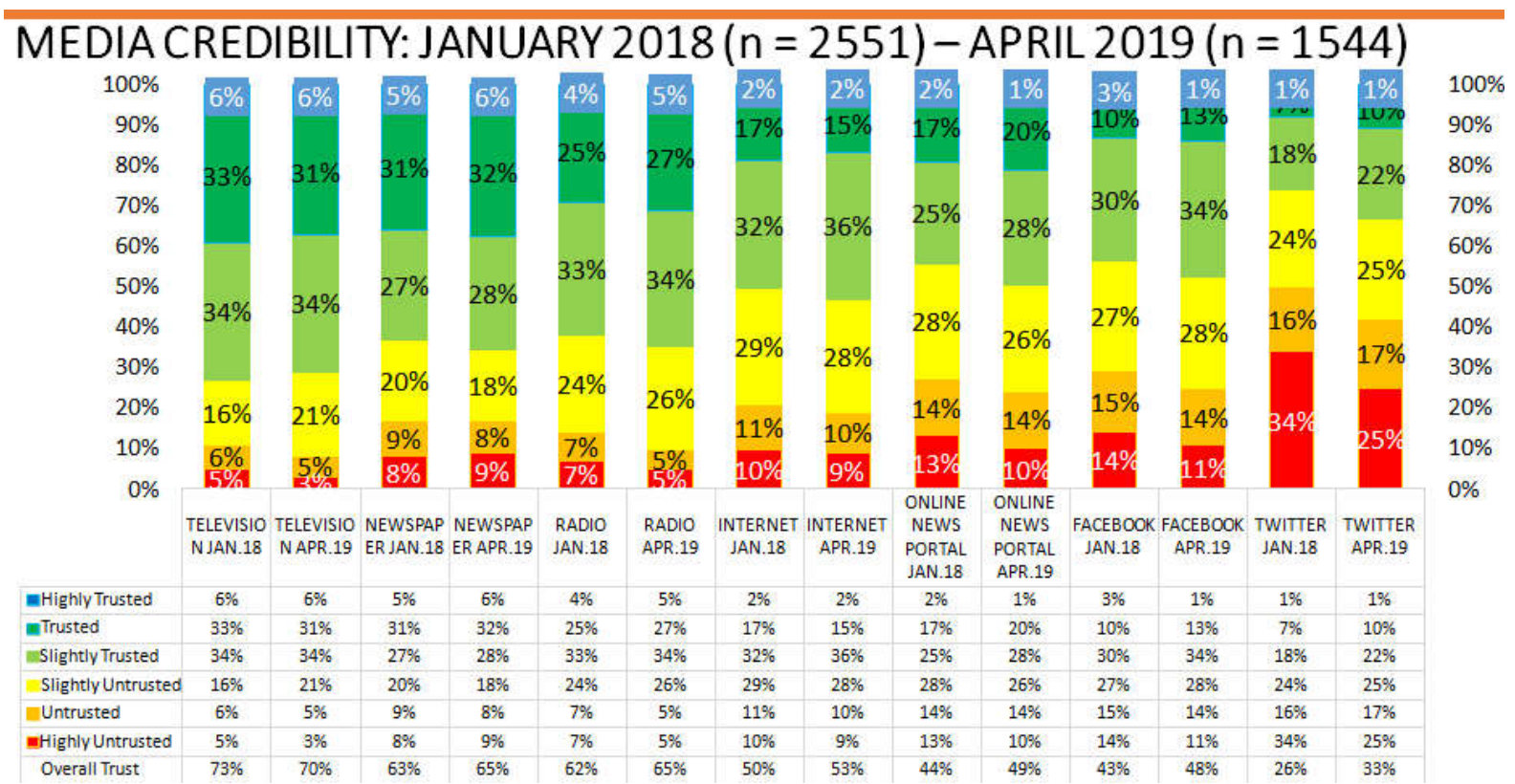

Figure 1: credibility of traditional and new media 


\section{DISCUSSION AND CONCLUSION}

The results of this study were in line with previous work (Flanagin \& Metzger, 2001; Gaziano \& McGrath, 1986; Roper, 1978; Tanta, Barić-Šelmić \& Levak, 2017; Vergeer, 2018 ) that the audience perceive traditional media as more credible than new media. The TV was perceived as the most credible medium in this study as the findings with many of the above mentioned studies. These results perhaps have a link with media use and exposure as discussed by Flanagin \& Metzger, (2001) that the respondents who have used traditional media more that new and their results showed that traditional media is more credible than new media.

Perceiving the new media as less credible than traditional media might be related to the argument of Vergeer, (2018) that disseminating false and incorrect information by new media make the new media more sceptical. Another reason for the high credibility refers to the discussion of (Banning \& Sweetser, 2007 Noor, 2017) that use of media that go through gatekeeping process especially traditional media which make these mediums more credible than the new media.

\section{References}

Abel, J. D., \& Wirth, M. O. (1977). Newspaper vs. TV credibility for local news. Journalism Quarterly, 54(2), 371-375.

Adeyanju, A. (2015). Comparative Study of Social Media, Television and Newspapers' News Credibility. International Conference on Communication, Media, Technology and Design. Dubai, United Arab Emirates, pp 69-77.

Anuar, M. K. (2010). Commentary: Teaching 'best practices' of journalism in Malaysia. Asia Pacific Media Educator, 1(20), 177-182.

Appelman, A., \& Sundar, S. S. (2016). Measuring message credibility: Construction and validation of an exclusive scale. Journalism \& Mass Communication Quarterly, 93(1), 59-79.

Armstrong, C. L., \& Collins, S. J. (2009). Reaching out: Newspaper credibility among young adult readers. Mass Communication and Society, 12(1), 97-114.

Atwood, L. E. (1985). Perceptions of the media: a review of selected source credibility. Ecquid Novi, 6(2), 87-104.

Azlan, A. A., Rahim, S. A., Basri, F. K. H., \& Hasim, M. S. (2012). Malaysian newspaper discourse and citizen participation. Asian Social Science, 8(5), 116.

Bae, S. W., Wright, L. B., \& Taylor, R. D. (2001). Print advertising context effects: the influence of media credibility on advertisement credibility. Journal of Promotion Management, 6(1-2), 73-88.

Banning, S. A., \& Sweetser, K. D. (2007). How much do they think it affects them and 
whom do they believe?: Comparing the third-person effect and credibility of blogs and traditional media. Communication Quarterly, 55(4), 451-466.

Bishop, R. L., Boersma, M., \& Williams, J. (1969). Teen-agers and News Media: Credibility Canyon. Journalism Quarterly, 46(3), 597-599.

Blake, K. R. (2002). NRJ Research in Brief: Has Newspaper Credibility Mattered? A Perspective on Media Credibility Debate. Newspaper Research Journal, 23(1), 73-77.

Bracken, C. C. (2006). Perceived source credibility of local television news: The impact of television form and presence. Journal of Broadcasting \& Electronic Media, 50(4), 723-741.

Bucy, E. P. (2003). Media credibility reconsidered: Synergy effects between on-air and online news. Journalism \& Mass Communication Quarterly, 80(2), 247-264.

Bucy, E. P., D’Angelo, P., \& Bauer, N. M. (2014). Crisis, credibility, and the press: A priming model of news evaluation. The International Journal of Press/Politics, 19(4), 453-475.

Carter, R. F., \& Greenberg, B. S. (1965). Newspapers or television: Which do you believe?. Journalism Quarterly, 42(1), 29-34.

Cheng, B. K. L., \& Lo, W. H. (2012). Can news be imaginative? An experiment testing the perceived credibility of melodramatic animated news, news organizations, media use, and media dependency. Electronic News, 6(3), 131-150.

Choi, J. H., Watt, J. H., \& Lynch, M. (2006). Perceptions of news credibility about the war in Iraq: Why war opponents perceived the Internet as the most credible medium. Journal of Computer-Mediated Communication, 12(1), 209-229.

Choi, Y., Axelrod, D., \& Kim, J. (2015). Trust me, I am your news channel: Media credibility across news platforms in the United States and South Korea. Electronic News, 9(1), 17-35.

Chung, C. J., Nam, Y., \& Stefanone, M. A. (2012). Exploring online news credibility: The relative influence of traditional and technological factors. Journal of Computer-Mediated Communication, 17(2), 171-186.

DeGroot, J. M., Young, V. J., \& VanSlette, S. H. (2015). Twitter use and its effects on student perception of instructor credibility. Communication Education, 64(4), 419-437.

de Vreese, C. H., \& Neijens, P. (2016). Measuring media exposure in a changing communications environment. Communication Methods and Measures, 10(2-3), 69-80.

Edelstein, A. S., \& Tefft, D. P. (1974). Media credibility and respondent credulity with respect to Watergate. Communication Research, 1(4), 426-439. 
Fico, F., Richardson, J. D., \& Edwards, S. M. (2004). Influence of story structure on perceived story bias and news organization credibility. Mass Communication \& Society, 7(3), 301-318.

Fishbein, M., \& Hornik, R. (2008). Measuring media exposure: An introduction to the special issue. Communication Methods and Measures, 2(1-2), 1-5.

Flanagin, A. J., \& Metzger, M. J. (2000). Perceptions of Internet information credibility. Journalism \& Mass Communication Quarterly, 77(3), 515-540.

Flanagin, A. J., \& Metzger, M. J. (2001). Internet use in the contemporary media environment. Human communication research, 27(1), 153-181.

Flanagin, A. J., \& Metzger, M. J. (2007). The role of site features, user attributes, and information verification behaviors on the perceived credibility of web-based information. New Media \& Society, 9(2), 319-342.

Francke, H., \& Sundin, O. (2012). Negotiating the role of sources: Educators' conceptions of credibility in participatory media. Library \& Information Science Research, 34(3), 169-175.

Gaziano, C., \& McGrath, K. (1986). Measuring the concept of credibility. Journalism quarterly, 63(3), 451-462.

Golan, G. J. (2010). New Perspectives on Media Credibility Research. American Behavioral Scientist, 54(1), 3-7.

Greenberg, B. S., \& Miller, G. R. (1966). The effects of low-credible sources on message acceptance. Communications Monographs, 33(2), 127-136.

Hovland, C. I., \& Weiss, W. (1951). The influence of source credibility on communication effectiveness. Public opinion quarterly, 15(4), 635-650.

Idid, S. A., \& Wok, S. (2006). Credibility of television, newspaper and Internet with popular votes of Barisan National during elections by race. Jurnal Pengajian Media Malaysia: Malaysian Journal of Media Studies, 8(1), 41-56.

Imlawi, J., Gregg, D., \& Karimi, J. (2015). Student engagement in course-based social networks: The impact of instructor credibility and use of communication. Computers \& Education, 88, 84-96.

Jackob, N. G. E. (2010). No alternatives? The relationship between perceived media dependency, use of alternative information sources, and general trust in mass media. International Journal of Communication, 4(18), 589-606.

Jo, S. (2005). The effect of online media credibility on trust relationships. Journal of Website Promotion, 1(2), 57-78.

Johnson, J. D. (1984). Media exposure and appraisal: Phase II, tests of a model in 
Nigeria. Journal of Applied Communication Research, 12(1), 63-74.

Johnson, T. J., \& Kaye, B. K. (1998). Cruising is believing?: Comparing Internet and traditional sources on media credibility measures. Journalism \& Mass Communication Quarterly, 75(2), 325-340.

Johnson, T. J., \& Kaye, B. K. (2000). Using is believing: The influence of reliance on the credibility of online political information among politically interested Internet users. Journalism \& Mass Communication Quarterly, 77(4), 865-879.

Kaufman, D. Q., Stasson, M. F., \& Hart, J. W. (1999). Are the tabloids always wrong or is that just what we think? Need for cognition and perceptions of articles in print media. Journal of Applied Social Psychology, 29(9), 1984-2000.

Kim, D., \& Johnson, T. J. (2009). A shift in media credibility: Comparing Internet and traditional news sources in South Korea. International Communication Gazette, 71(4), 283-302.

Kiousis, S. (2001). Public trust or mistrust? Perceptions of media credibility in the information age. Mass Communication \& Society, 4(4), 381-403.

Li, X. (2018). Media exposure, perceived efficacy, and protective behaviors in a public health emergency. International Journal of Communication, 12 (20), 26412660 .

McCroskey, J. C., \& Young, T. J. (1981). Ethos and credibility: The construct and its measurement after three decades. Communication Studies, 32(1), 24-34.

McGrath, K., \& Gaziano, C. (1986). Dimensions of media credibility: Highlights of the 1985 ASNE survey. Newspaper Research Journal, 7(2), 55-67.

Mehrabi, D., Hassan, M. A., \& Ali, M. S. S. (2009). News media credibility of the internet and television. European Journal of Social Sciences, 11(1), 136-148.

Melican, D. B., \& Dixon, T. L. (2008). News on the net: Credibility, selective exposure, and racial prejudice. Communication Research, 35(2), 151-168.

Metzger, M. J., \& Flanagin, A. J. (Eds.). (2008). Digital media, youth, and credibility. London: MIT press.

Metzger, M. J., Flanagin, A. J., Eyal, K., Lemus, D. R., \& McCann, R. M. (2003). Credibility for the 21st century: Integrating perspectives on source, message, and media credibility in the contemporary media environment. Annals of the International Communication Association, 27(1), 293-335.

Meyen, M., \& Schwer, K. (2007). Credibility of media offerings in centrally controlled media systems: a qualitative study based on the example of East Germany. Media, Culture \& Society, 29(2), 284-303.

Morris, M. R., Counts, S., Roseway, A., Hoff, A., \& Schwarz, J. (2012, February). 
Tweeting is believing?: understanding microblog credibility perceptions. $A C M$ 2012 conference on Computer Supported Cooperative Work. Washington, pp.441-450.

Mulder, R. (1980). Media credibility: A use-gratifications approach. Journalism Quarterly, 57(3), 474-477.

Mustaffa, N., Ibrahim, F., Samani, M. C., \& Rahim, M. H. A. (2010). Persepsi Khalayak Terhadap Kredibiliti Media di Malaysia. Jurnal eBangi, 5(2),153-160.

Newhagen, J., \& Nass, C. (1989). Differential criteria for evaluating credibility of newspapers and TV news. Journalism Quarterly, 66(2), 277-284.

Noor, R. (2017). Citizen journalism vs mainstream journalism: a study on challenges posed by amateurs. Athens Journal of Mass Media and Communication, 3(1), $55-76$.

Ohanian, R. (1990). Construction and validation of a scale to measure celebrity endorsers' perceived expertise, trustworthiness, and attractiveness. Journal of advertising, 19(3), 39-52.

Oyedeji, T. (2011). Credibility perceptions of different types of weblogs among young adults. Global Media Journal, 11(19), 1-14.

Perloff, R. M. (2003). The dynamics of persuasion: Communication and attitudes in the 21st century. New Jersey: Lawrence Erlbaum Associates.

Poler Kovačič, M., Erjavec, K., \& Štular, K. (2010). Credibility of Traditional vs. Online News Media: A Historical Change in Journalists' Perceptions?. Medijska istraživanja, 16(1), 113-130.

Qader, I. K. A., \& Zainuddin, Y. (2011). The influence of media exposure, safety and health concerns, and self-efficacy on environmental attitudes towards electronic green products. Asian Academy of Management Journal, 16(2), 167-186.

Rimmer, T., \& Weaver, D. (1987). Different questions, different answers? Media use and media credibility. Journalism Quarterly, 64(1), 28-44.

Roper, B. W. (1978). Changing Public Attitudes toward Television and Other Media 1959-1976. Communications, 4(2), 220-238.

Salman, A., Ibrahim, F., Abdullah, M. Y. H., Mustaffa, N., \& Mahbob, M. H. (2011). The impact of new media on traditional mainstream mass media. The Innovation Journal: The Public Sector Innovation Journal, 16(3), 1-11.

Shariff, S. M., Zhang, X., \& Sanderson, M. (2017). On the credibility perception of news on Twitter: Readers, topics and features. Computers in Human Behavior, 75, 785-796.

Shen, F., Lu, Y., Guo, S., \& Zhou, B. (2011). News media use, credibility, and efficacy: 
An analysis of media participation intention in China. Chinese Journal of Communication, 4(4), 475-495.

Slater, M. D. (2004). Operationalizing and analyzing exposure: The foundation of media effects research. Journalism \& Mass Communication Quarterly, 81(1), 168-183.

Srinivasan, M., \& Barclay, F. P. (2017). Media credibility: A triangulation test. Journal of Content, Community \& Communication, 6, 43-49.

Starck, K. (1969). Media credibility in Finland: A cross-national approach. Journalism Quarterly, 46(4), 790-795.

Sundar, S. S. (1999). Exploring receivers' criteria for perception of print and online news. Journalism \& Mass Communication Quarterly, 76(2), 373-386.

Sweetser, K. D., Porter, L. V., Chung, D. S., \& Kim, E. (2008). Credibility and the use of blogs among professionals in the communication industry. Journalism \& Mass Communication Quarterly, 85(1), 169-185.

Tanta, I., Barić-Šelmić, S., \& Levak, T. (2017). The Level of Credibility of Traditional and New Media in Reporting on Human Rights Issues. Collegium antropologicum, 41(3), 215-229.

Tseng, S., \& Fogg, B. J. (1999). Credibility and computing technology. Communications of the ACM, 42(5), 39-44.

Vergeer, M. (2018). Incorrect, fake, and false. Journalists' perceived online source credibility and verification behavior. Observatorio (OBS*), 12(1), 37-52.

Wanta, W., \& Hu, Y. W. (1994). The effects of credibility, reliance, and exposure on media agenda-setting: A path analysis model. Journalism Quarterly, 71(1), 9098 .

Webster, J. G. (2016). Why study measures of exposure? From exposure to attention. Communication Methods and Measures, 10(2-3), 179-180.

Westley, B. H., \& Severin, W. J. (1964). Some correlates of media credibility. Journalism Quarterly, 41(3), 325-335.

Wok, S., Tamam, E., \& Bolong, J. (2010). Pattern of the news media consumption and news discussion among youth: A test of agenda setting theory. International Communication and Media Conference (ICOME"10) Communication and Society: Challenges and Engagement. Universiti Utara Malaysia (UUM), Kuala Lumpur, pp. 1-25.

Yamamoto, M., \& Nah, S. (2017). A Multilevel Examination of Local Newspaper Credibility. Journalism \& Mass Communication Quarterly, 95(1), 76-95. 


\section{Biodata}

Syed Arabi Idid is a Professor of Communication in the Department of Communication at the International Islamic University Malaysia. His areas of interest include Public relations, communication theories and research. He wrote many books and published many articles in these fields.

Shahrul Nazmi Sannusi is a senior lecturer at Centre for Communication and Digital Society, Faculty of Social Sciences and Humanities, Universiti Kebangsaan Malaysia. His area of expertise is in journalism and public relations.

Mohammed Fadel Arandas obtained his Ph.D in Communication from Centre for Communication and Digital Society, Faculty of Social Sciences and Humanities, The National University of Malaysia. He obtained his Master in Communication from the Department of Communication, at the International Islamic University Malaysia. 